and, as the literature of protein chemistry shows, has been used to good effect. The difficulties have been widely enough discussed and publicized. If Professor Kenner feels that the practical advantages of the solid-phase method are all a great delusion, then I am sure no one will be listened to with greater interest.

\section{Economics and Ecology}

SIR,-Of recent years it has seemed that the needs of our environment, as seen by ecologists, and the needs of process technologists, epitomized by the laws of economics, were irrevocably opposed. We need to seek any means for moderating this conflict. One of the contentious issues is the limited term of years for which patents run. It is in the early years that a manufacturer may make most profit from a valuable patented process. Moreover, the operative term of years runs from the sealing date. The manufacturer is unlikely willingly to accept the advice of an ecologist that several years may be needed to evaluate whether by-products from working a patent will or will not harm the environment.

After three months or so an application for a patent may be granted. If, then, the patentee does not arrange for the use of the process which is the subject of the patent the monopoly rights may be lost. No provision is made for delay while ecological studies assess whether working the patent may damage the environment. Notoriously ecologists find it difficult to give straight answers to straight questions posed by technologists, but the more the time that is available the easier it is to arrive at a straightforward answer. Since three years is probably a minimum time to obtain sufficient information to attempt reasonably confident judgments, I suggest as a compromise that the needs of environmental protection would be furthered if the operational date for a patent covering a chemical process could be deferred for, say, three years after the sealing or granting date.

The decision as to whether such ecological evaluation is necessary would be made by Patent Office examiners, acting on the advice of environmental ecologists on the staff of governmental laboratories such as those of the Ministry of Agriculture, Fisheries and Food or the Water Pollution Research Laboratory.

The necessary assessment of the environmental consequences of newly patented processes could be referred to an ecological laboratory which might well develop under the wing of the Government Chemist but be largely financed by fees from firms soliciting patent protection for new processes. This laboratory would assess the environmental hazards inherent in new processes submitted for Letters Patent. Its reports could include statements of the kinds of treatment needed to render harmful effluents harmless and would be submitted back to the Patent Office whose examiners would have acquired the experience to check, evaluate and implement the ecological findings.

A process patent, tentatively sealed under the present patent laws, would become operational only on the date of approval by the ecological examiners and with any operational restrictions which they might think fit to impose.

During the period of evaluation the manufacturer would be protected from pirating of his process and would then have the full term of years in which to exploit his patent. The environment would be protected much more than it now is. Economics and ecology would learn to live together.

Any country which unilaterally adopted such a development of Patent Law would place its manufacturers at a disadvantage compared with manufacturers which did not have to work within such a law. Clearly international agreement would be needed before any country could enforce such a law.

There may be circumstances in which a manufacturer, introducing a new process which he knew could provide a hazard to the environment, would circumvent the law by the simple expedient of not applying for patent protection. To meet this situation the law would need to contain the provision that a new emission to the environment of any substance or form of energy is presumed to be hazardous to the environment until it has been proved not to be so to the satisfaction of the appropriate Inspecting Officer or Patent Examiner.

To sum up, wise international development of the Patent Laws could provide effective control of adverse effects of new technological emissions upon the environment.

$$
\begin{aligned}
& \text { Yours faithfully, } \\
& \text { L. H. N. CoOPER }
\end{aligned}
$$

The Laboratory,

Citadel Hill,

Plymouth

\section{Insect Taxonomy}

SIR,-It is not only in Britain that insect taxonomy is regrettably so neglected (Nature, 238, 475; 1972). The same situation obtains in many other countries. I am told by colleagues abroad, and am a witness to the problem myself, that the always notoriously limited financial and moral support for this field of enquiry is in fact decreasing yearly. In this context, the following points may prove of some interest.

(1) Registration of existing species, and arranging them into a system which would make possible reasonable orientation in an immense insect diversity, species identification, and suitable classification of any kind of information on insects - these are the primary goals of insect taxonomists. But because of the imbalance between the extent of the group (some 1,000,000 species recognized and several times as many still unknown) and the limited number of taxonomists on a world-wide scale, the field still suffers from substantial lacunae even in the most basic descriptive data.

(2) A vast amount of work has been done and is still being done by amateur entomologists. The result is that the layman cannot always understand how severely insect taxonomy is understaffed. Moreover, factors such as rising expenses of all kinds and the growing necessity for entomologists to gain a broader biological background logically render it difficult for amateurs to keep in step with the professionals.

(3) Insect taxonomists play a double role in society: they do research and they provide identification services. The importance of precise identification for applied biology, as well as for the standardization of biological material for further study, is generally recognized; but few people are aware how very frequently such services are required. Usually, reliable identification can only be undertaken by research taxonomists actively working in the pertinent groups of insects. Yet the world-wide shortage of experienced specialists frequently results in these services being provided by less qualified persons, with a consequent high percentage of misidentifications or nomenclatorial inaccuracies. Chronic scarcity of identification manuals, catalogues, cumulative faunal lists, and similar reference works is another consequence of this state of affairs.

(4) It is still possible to achieve serious and often outstanding scientific advances in insect taxonomy by the use of simple methods and with minimum expense. It is absurd to consider this a shortcoming or a reason for reduced monetary support; it would be equally ludicrous to look down on insect taxonomy as an obsolete science where "everything has already been done" simply because it has been intensively pursued for more than two centuries. It cannot be stressed too emphatically that the taxonomic field necessitates not only extensive development of basic, descriptive and registratory work, but also substantial advances at the higher, synthetic and causal levels. This requires an interdisciplinary approach and consequently the use of varied 
experimental techniques, numerical methods, electron microscopy, etc. But projects of this kind are very far from achieving reality without funds comparable with those afforded to other, more "modern" branches of biology.

Insect taxonomists have contributed substantially to the advancement of science as well. as to everyday scientific practice. Most of the research work, however, still remains to be done, while it is also imperative to ensure the existence of reliable identification services. Both are the basic responsibility of taxonomists toward society. On the other hand, I am convinced it is the moral duty of science administrators to grant enough support for insect taxonomy to allow it to develop as progressively and successfully as other fields of biological enquiry.

\section{Yours faithfully,}

\section{JAN ZUSKA}

Department of Entomology,

Research Institute of Food Industry, Czech Academy of Agriculture,

$\mathrm{Na}$ bělidle 21,

Prague 5

\section{Faulty Flying Machine}

SIR, - I believe your readers would be concerned to hear of the unfortunate fate of a colleague who constructed a flying machine based upon a design of H. C. Bennet-Clark (Nature, 239, 451 ; 1972). The machine became airborne satisfactorily but when adjusting the trim to change from a subsonic to a supersonic condition it veered uncontrollably and, sadly to say, fatally to starboard.

Subsequent examination of the black box flight recorder yielded the last message from my colleague, couched in understandably uninhibited terms, to the effect that ".... the ... dotted line on the starboard fin should have been drawn through the ... corner".

Yours faithfully,

D. C. SPOONER

Research and Development Division, Cement and Concrete Association, Wexham Springs, Slough SL3 6PL

\section{IQ Absurdity}

SiR,-There appears to be an absurd recommendation towards the end of the first paragraph of "How much of IQ is inherited?" (Nature, 240, 69; 1972). You say, in effect, that, even where valid conclusions are being drawn from accurate observation of a phenomenon, policy makers should be absolved from paying them any attention. Using a closely similar example, may I point out the unsoundness of this notion?
It is the generally accepted view among psychologists that there is no inherent difference between the sexes in the distribution of IQ. I conclude, from your comments, that you would consider it entirely proper for this fact to be disregarded by social policy makers, on the grounds that it is likely to be irrelevant to decisions about, for example, equal treatment for the sexes at work. If this should not be a permissible conclusion for me to draw, I would welcome your explanation of the critical ways in which it differs logically from the argument which you have presented.

The emotional content of racial questions has a tendency to cloud real issues. I would like to suggest that the problem to which educational psychologists, social policy makers, and the editors of learned journals should be addressing themselves is that of providing suitable educational facilities for as wide a range of intellectual ability as possible. In this way, most people would receive treatment tailored to their special needs, and the colour of their skin would be seen for the red herring it is.

Yours faithfully, ANDREW M. StewarT

Imberdown, Woodlands Lane,

Liss,

Hampshire

\section{Law of the Sea}

SIR,- The article on "Threat to Deep Sea Research" (Nature, 239, 421; 1972) is misleading when it refers to permission usually being granted for work on the continental shelf. For example, Turkey insists that national organizations should participate. However, even when this condition is fulfilled the Turkish Government consistently refuses permission on security grounds. Similarly Greece usually insists that a naval observer is on board, but when this is welcomed and national organizations are participating by invitation, refuses permission for magnetic, gravity and bathymetric surveys.

These are two countries selected from many examples which could be quoted, but several other countries both in Europe and elsewhere are becoming increasingly restrictive, generally on "security" grounds. It is always easier to refuse permission than to grant it.

Yours faithfully, JoHN S. Tooms

Applied Geochemistry Research Group,

Department of Geology, Royal School of Mines,

Prince Consort Road, London SW7
Reports and Publications

not included in the Monthly Books Supplement

\section{Great Britain and Ireland}

Memoirs of the Royal Astronomical Society, Vol. 77. Part 1: Integrated Magnitudes and Colours o Bright Galaxies into the UBV System. By Gerard de Vaucouleurs and Antoinette de Vaucouleurs. Pp. Publications, 1972. Published for the Royal Astronomical Society)

Ministry of Agriculture, Fisheries and Food Fishery Ministry of Agriculture, Fisheries and Food. Fishery of Ostrea edulis (L.) in Relation to ise Cubtivation of Ostrea edulis (L.) in Relation to the Cultivation 95p net. No. 3: The Fishery for the Norway Lobster. Nephrops norvegicus (L.), of the North-east Coast of England. By D. J. Symonds. Pp. iiit 36. 95p net. London: HMSO, 1972.)

Thoughts on WSAC: Comments by the Inland Waterways Association on the Proposed Water Space Amenity Commission. Pp. 13. (London: The Inland Waterways Association Limited, 1972.) 1910 Department of Education and Science. Drugs and
the Schools. Pp. 20. (London: Department of Eduthe Schools. Pp. 20. (London: Department of Edu-
cation and Science, 1972.) Gratis. cation and Science, 1972.) Gratis. Water Pollution Department of the Environment. Water Pollution Research, 1971: Report of the Director of Water
Pollution Research. Pp. v+129. (London: HMSO Pollution Research. Pp. v+129. (London: HMSO,
[1010
[1.10 net. The Science-and Art-of Coal Mining. By N Siddall. (The Robens Coal Science Lecture delivered on Monday, 9h October, 1972.) Pp. 16. (London: The British Coal Utilisation Research Association.
Ltd., 1972.) Department of the Environment and Welsh Office. Statistics for Town and Country Planning. Series I Planning Decisions. No. $4:$ Statistics of Decisions on Planning Applications, 1971, England and Wales. Science Museum Library. Science Library Bibliographical Series No. 800 : Some References on Theories of Mechanisms of Action of General Anaesthetics, 1875-1970. Pp. 3. (London: Science Museum
Library, 1972.)
Kidney Disease and Incapacity. Pp. 10. (London: National Kidney Research Fund, 54 Paddington Street, 1972.) 20p. Department of the Environment and the Welsh Updated 1972-River Quality. Pp. vi 16. (London:
HMSO, 1972.) 30p net.

Building Research Station. Digest 69: Durability and Application of Plastics. Pp. 8. 5p. Digest 146: Modernising Plumbing Systems. Pp. 4. 5p. (London: HMSO, 1972.)

Proceedings of the Royal Irish Academy. Vol 72 Section A, No. 9: On the Modes of Decay for the Wave Equation in the Exterior of a Reflecting Body. By Cathleen Synge Morawetz. Pp. 113-120. 16p. Vol. 72, Section B. No. 12: An Ordovician Whiterock Fauna in Western Ireland. By A. Williams. Pp. 209-220+ plates 10 and 11. 21p. No. 13: Palaeomagnetic Evidence for the Rotation of North Co. Dublin. Pp. 221-228. 10p. No. 14: A Study of the High Energy Phosphates and Anaerobic Glycolysis in the Red and White Fibres of Porcine Semitendinosus Muscle. By P. J. V. Tarrant, P. V. J. Hegarty and
J. V. McLoughlin. Pp. 229-251. 36p. (Dublin: V. McLoughlin. Pp. 229-251. 36p. (Dublin:
[1210 The Scottish Horticultural Research Institute. 18th Annual Report for the year 1971. Pp. 84. (Invergowrie, Dundee: The Scottish Horticup VAT and Car Tax: Tax-free Sales of Motor Vehicles to Tourists, etc. Pp. 6. (London: HM Vehicles to Tourists. etc. Pp. 6. (London: HM
Customs and Excise, 1972.) Induced Abortion. (A report on the meeting of the IPPF Panel of Experts on Abortion.) Pp. 38 40 ; $\$ 1$. Vasectomy. Edited by R. L. Kleinman.

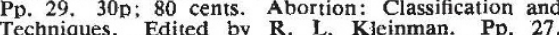
T0chniques. Edited by R. L. Kleinman. Pp. 27. R. L. Kleinman. Pp. 39. 40p; \$1. (London: InterR. L. Kleinman. Pp. 39. 40p; \$1. (London: InterTobacco Consumption in Various Countries. Edited by D. H. Beese. Third edition. Pp. 66. (London:

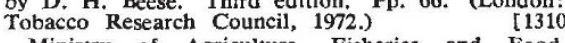
Ministry of Agriculture, Fisheries and Food. Fishery Investigations, Series II, Volume 27. No. 4: movelopments in the Laboratory Culture of the ComWickins. Pp. iii 23, 76p net. No. 5: Experiments on the Culture of the Spot Prawn Pandalus platyceros Brandt and the Giant Freshwater Prawn Macrobrachium rosenbergii (de Man). By John F. Wickins. Pp. vii 23. $90 \mathrm{p}$ net. No. 6: The Movements of Tagged Adult Plaice in the Irish Sea. By C. T Macer. Pp. v+41. £1.05 net. (London: HMSO.

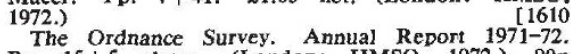
The Ordnance Survey. Annual Report 1971-72.
Pp. 15+5 plates. (London: HMSO, 1972.) 90p net.
University of Oxford. Oration by the Vice-Chancellor and Annual Report 1971-1972. Pp. 49-72. (Oxford: The University, 1972.) 10p. [1810 Department of the Environment. Circular 103/72: Compensation, Blight and Rehousing. Pp. 6. Development and Compensation-Putting People First. (Cmnd. 5124.) Pp. jiit 19. 16p net. New Roads in Towns: Report of the Urban Motorways Committee to the Secretary of State for the Environment. Pp. xi $+44.37 p$ net. Circular $102 / 72$ : Land Availability
for Housing. Pp. 10. 11p net. (London: HMSO, 1972.) 